\title{
Subjective Happiness among the Elderly across Various Groups
}

\author{
${ }^{1}$ Pallavi Shukla \& ${ }^{2}$ U.V.Kiran \\ ${ }^{I}$ Student \& ${ }^{2}$ Assistant Professor \\ ${ }^{I}$ Department of Human Development \& Family Studies School for home science \\ ${ }^{2}$ Babasaheb Bhimrao Ambedkar University (A Central University) Vidya Vihar, Raebarelli Road
} Lucknow-226025

\begin{abstract}
Adjustment in old age is difficult because of the limited capacity of the old, their diminishing energy and declining mental abilities. The degree of success depends upon the individual's adaptability. The needs and problems of the elderly vary significantly according to their age, health, home, social, marital emotional and financial aspect. The present study is an attempt to study the patterns of adjustment among elderly. The sample comprised of 200 elderly people (100 male, 100 female) of Lucknow city in the age group of 60 years and above. Multistage random sampling technique was employed for sample selection. Interview schedule was framed to collect the required information given by the respondent. From the findings of the study its can be seen that subjective happiness among urban elderly is higher in male and female in comparison to elderly staying in rural area. The subjective happiness of male elderly staying in nuclear families is higher in comparison to elderly staying in joint families. Nonworking females generally were happy in comparison to working elderly.
\end{abstract}

Key words: Subjective happiness, elderly.

\section{Introduction}

The pattern of family life, established in old age, starts to change with the onset of middle age. These changes are made more pronounced by retirement, with the accompanying reduced income, or by the death of spouse in old age. Of the many adjustments centering around family relationships that the elderly person must make, the five most important involve relationship with a spouse, changes in sexually behavior, relationship with off-spring, parental dependency and relationship with grandchildren. (Hurlock 2002)

Old age often brings a deterioration of circumstances in some ways, but a decline in happiness appears to be avoidable. Social isolation tends to increase, partly due to the end of working life or the loss of a spouse or close friends (Lelkes 2010). Ageing may imply a mental decline, or a loss of cognitive capacity (Rohwedder and Willis 2010). Subjective well-being also declines on average. The literature on ageing and happiness tends to conclude that there is a U-shape, with the elderly being better off than the middle aged (Blanchflower and Oswald 2008; Frijters and Beatton 2012), but this holds only if we control for other characteristics and life events which are typical of old age (lower education, worse health, lower incomes, loss of spouse) (Lelkes 2007). This raises the question of whether old age could be a golden age of life, a period with a deep sense of fulfillment and happiness, if we were able to avoid some negative aspects of old age

Successfully men and women will adjust to the problems arising from the physical and mental changes that accompany aging and from the changes in status that occur at this time will be influenced by many factors, some of which are beyond their control. There are many criteria that can be used to assess the kind of adjustment elderly people make, four of which are especially useful. They are quality of behavior patterns, changes in emotional behavior, personality changes and life satisfaction or happiness. Those who have not prepared themselves psychologically or economically for the changes that old age inevitably brings often find adjusting to those changes a traumatic experience. The difficulties experienced in adjusting to old age are often the result of earlier learning of certain forms of adjustment that are not appropriate to this period of the life span. (Hurlock 2002)

To be well adjusted in old age men and women must be able to satisfy their personal needs and live up to the expectations of others within the framework of life provided for them. The more old friendship the Elderly are able to retain, the better adjusted and happier they will be moving to other areas or outliving their friends militates against this. Attitudes of grown children towards their elderly parents and frequent associations with them contribute to good personal and social adjustment on the part of the Elderly. A resistant attitude toward aging and to adjustment to changes in aging brings is a serious obstacle to successful adjustment in old age.

When they feel that they are neglected by their grown children or other family members, when they develop a "nobody loves me" complex, it is inevitable that they would be unhappy (Hurlock 2002). Regardless 
of social class, sex or any other demographic-chanter, certain condition can be counted on to contribute to subjective happiness in clearly age. Even though all these conditions contribute to happiness in old age, it is not essential that they all be present in order for the elderly person to be happy.

Some studies show that the elderly may be more prone to depression and loneliness, which can lead to higher rates of unhappiness, not a surprise given the health and emotional challenges that tend to accompany aging. But increasing, more and more studies suggest that happiness may actually rise after middle age - at least when scientists take into account some of the non-biological factors that can influence reports of contentment.

In a new study, which was published in Psychological Science, researchers led by Angelina Sutin of Florida State University College of Medicine examined data from two large samples of people; one included nearly 2,300 primarily white and highly educated people with an average age of 69 living in a Baltimore community between 1979 and 2010. The second group included reports of well-being collected in the 1970s from a representative sample of some 3,000 adults from the U.S. population who were in their late $40 \mathrm{~s}$ and $50 \mathrm{~s}$ at the time of the study.

Furthermore, because people have different needs, what bring happiness to one in old age may not bring happiness to another. On the other hand, because the pattern of life that bring happiness in old age is usually similar to the pattern that brought happiness in the closing year of life is the opportunity to continue the lifestyle that previously led to happiness (Hurlock 2002). The present study intends to examine the variation in subjective happiness among elderly due to the area of domicile, family type and their working status.

\section{Methodology}

Qualitative research design was adopted to carry out the present study was conducted in rural and urban areas of Lucknow district, Uttar Pradesh. The sample consists of 200 elderly in the age group 60 years above. Elderly with a diagnosed mental illness or serious health problem, persons remarried, persons residing with a relative's family, Persons living with 4th generation, were excluded from the study Multi stage random sampling technique was adopted to draw a sample of 200 comprising of 100 rural and 100 urban elderly.

A Demographic data sheet was used to collect the general information of the respondents. Subjective happiness was assessed using subjective happiness scale by Lymboomirsky and Lepper (1999). The required information was collected through interview method and observation method was used to cross check the information given by the respondents. Comparison was done between the groups and result was analyzed using Mean, S D \& t Test as statistical tools, using spss software.

\section{Results and Discussion}

Table 1: Subjective happiness of male and female elderly according to the area of domicile

\begin{tabular}{|c|c|c|c|c|c|c|}
\hline & \multicolumn{5}{|c|}{ Area } & \\
\hline \multirow[t]{2}{*}{ Variable } & \multicolumn{2}{|c|}{ Rutral } & \multicolumn{2}{|c|}{ Urban } & & \\
\hline & Mean & S.D & M & SD & $\mathrm{T}$ & Sig. \\
\hline Male & 25.26 & 6.43 & 28.30 & 4.55 & .323 & .571 \\
\hline Female & 19.9 & \begin{tabular}{|l|l|}
7.04 \\
\end{tabular} & 28.30 & .53 & 05 & \begin{tabular}{|l|}
.943 \\
\end{tabular} \\
\hline
\end{tabular}

From the data, it is evident that the subjective happiness among male and female staying in urban areas is equal ( $\mu=28.3$ and high in comparison to elderly staying in rural areas. Among the elderly studying in rural areas male elderly comparatively are hippies t5han female elderly $(\mu=19.9)$. Though no significant difference exist among elderly

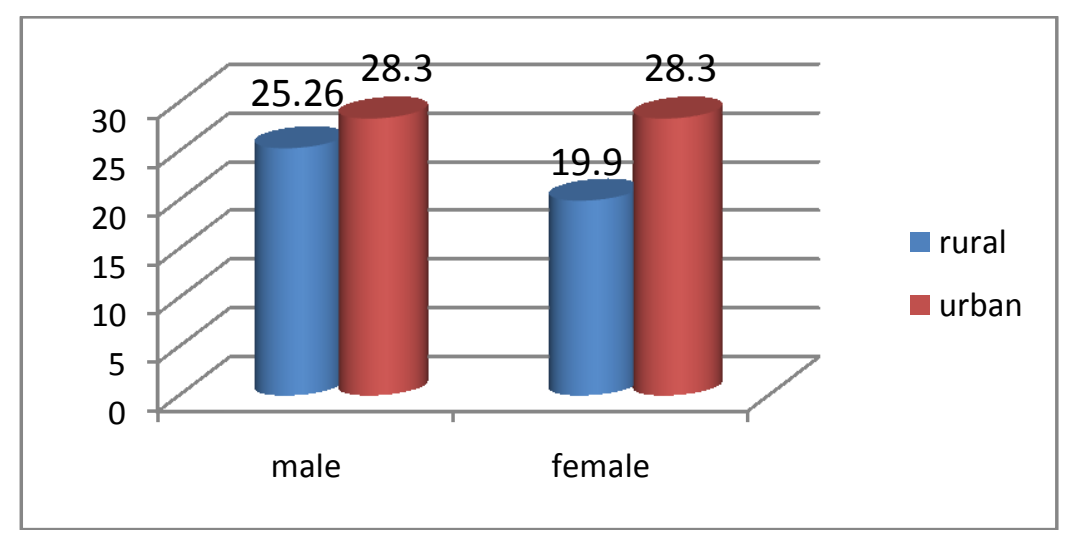

. Fig 1 (a). Subjective happiness of male and female elderly according to their area 
Table 2 Subjective happiness of male and female elderly according to their type of family

\begin{tabular}{|l|l|c|c|c|c|l|}
\hline \multirow{2}{*}{ Variable } & \multicolumn{5}{|c|}{ Type of family } \\
\cline { 2 - 7 } & \multicolumn{2}{|c|}{ Nuclear } & \multicolumn{2}{c|}{ Joint } & & \\
\hline & Mean & S.D & $\mathrm{M}$ & $\mathrm{SD}$ & $\mathrm{T}$ & Sig. \\
\hline Male & 28.56 & 5.0 & 28.00 & 4.02 & 1.36 & .248 \\
\hline Female & 28.48 & 3.13 & 27.57 & 5.59 & .349 & .552 \\
\hline
\end{tabular}

The differences in subjective happiness among nuclear and joint family was also seen and it was found that among male elderly, subjective happiness was higher in joint family in comparison to nuclear families. The subjective happiness of female elderly staying in nuclear families is higher in comparison to joint families.

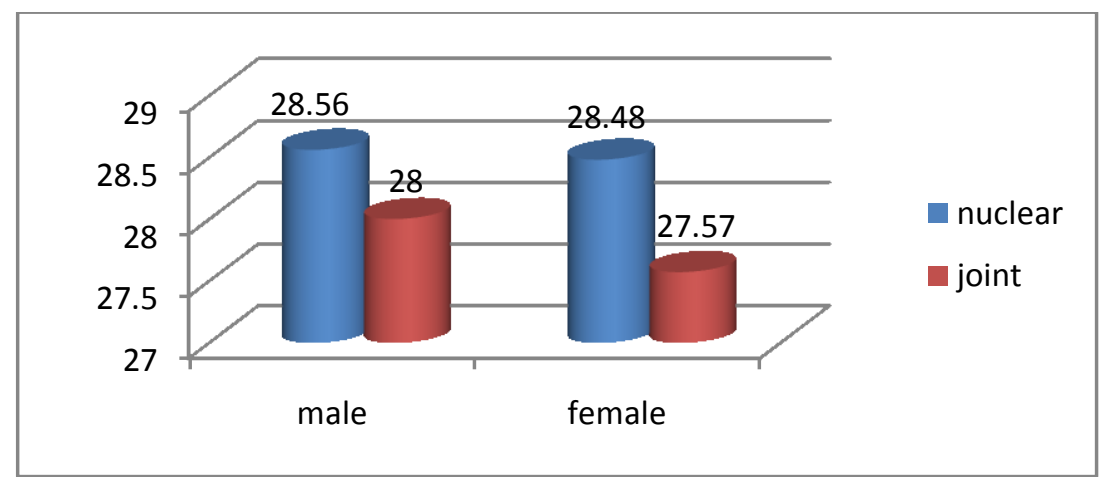

Fig 1. (b) . Subjective happiness of male and female elderly according to, type of family

Table 3 Subjective happiness of male and female elderly according to their working status

\begin{tabular}{|c|c|c|c|c|c|c|}
\hline & \multicolumn{6}{|c|}{ Working status } \\
\hline & \multicolumn{2}{|c|}{ Working } & \multicolumn{2}{|c|}{ Non working } & \multirow[b]{2}{*}{$\mathrm{T}$} & \multirow[b]{2}{*}{ Sig. } \\
\hline & Mean & S.D & $\mathrm{M}$ & SD & & \\
\hline Male & 26.72 & 5.99 & 29.19 & 3.29 & $4.04 *$ & .09 \\
\hline Female & 29.11 & 4.04 & 27.8 & 4.69 & $4.34^{*}$ & .042 \\
\hline
\end{tabular}

The above table explains the impact of subjective happiness in different working status. In both areas significant differences are seen. But the impact of working status on their subjective happiness indicated that male $\&$ female who are not working feel happy than working elderly.

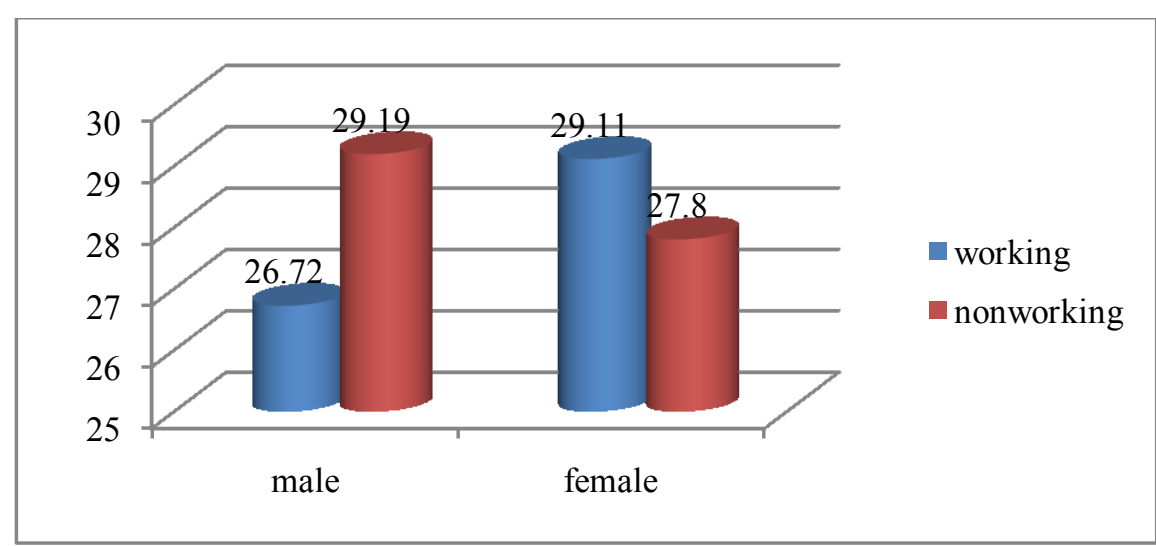

Fig 3(c). Happiness of male and female elderly according to working status 


\section{Conclusion}

The study is regarding the age limit set by the study. The study includes the elderly who are 60 years and above therefore, the findings should be interpreted with caution. The limitation of the study in area only covered urban and rural. The present study was conducted on 200 elderly people of Lucknow city.100 elderly living in rural and 100 elderly living in urban area. Both the group divided in to 50 male and 50 female were randomly selected. An Interview schedule was framed to collect the required information. The impact of subjective happiness of urban elderly is higher in male in comparison to elderly staying in rural area. The subjective happiness of male elderly staying in nuclear families is higher in comparison to elderly staying in joint families. Elderly staying in nuclear families are happier in comparison to joint families. Non working females generally were happy in comparison to working elderly.

\section{Reference}

[1]. Blanchflower, D. G. and A. Oswald (2008). "Is Well-being U-Shaped over the life cycle?" Social Science \& Medicine 66(8): 17331749 .

[2]. Frijters, P. and T. Beatton (2012). "The mystery of the U-shaped relationship between happiness and age " Journal of Economic Behavior \& Organization 82(2-3): 525-542.

[3]. Lymboomirsky and Lepper (1999), subjective happiness scale

[4]. Rohwedder, S. and R. J. Willis (2010). "Mental Retirement." Journal of Economic Perspectives 24(1):119-38. Book reference

[5]. Hurlok B.Elizabeth. Deeloopmental psychology: A life- Span Approch, 5th ed. New Delhi: Tata Mcgraw-Hill Publishing Copany LTD; 2002 .

[6]. Lelkes, O. (2010). Social participation and social isolation. Income and living conditions in Europe.

[7]. Eurostat Statistical books. A. B. Atkinson and E. Marlier. Luxembourg, Publications Office of

[8]. the European Union: 217-240. Web reference

[9]. http://healthland.time.com/2013/02/18/with-age-comes-happiness/. 